\title{
Formação de professores: a questão da inclusão de jovens que estão fora da escola e do mercado de trabalho
}

\section{Teacher formation: questions about the inclusion of young people who are out of school and labor market}

\author{
Luís Távora Furtado Ribeiro ${ }^{1}$
}

\begin{abstract}
RESUMO
Este artigo analisa os resultados de um programa de escolarização em nível supletivo ofertado pela Secretaria de Educação do Estado do Ceará, cujo objetivo visa facilitar o ingresso no ensino superior de jovens moradores de um bairro de Fortaleza, com população que apresenta alto índice de desemprego, violência e consumo de drogas. A partir da análise de dados de pesquisa sobre essa experiência, discutem-se problemas da Educação Brasileira relacionados à inclusão de jovens que estão fora da escola e do mercado de trabalho, visando sua inserção social em processos educativos e culturais. Com base no pensamento de Paulo Freire e da educação popular, defende-se a formação de professores num contexto educativo que valorize a cooperação e a construção coletiva de conhecimentos envolvendo docentes, monitores e alunos como sujeitos da ação educativa ${ }^{2}$.

Palavras-chave: educação popular; juventude; escolarização; formação de professores.
\end{abstract}

\footnotetext{
ABSTRACT

This article analyzes the results of a schooling program, offered by the Ceará State Education Department, with the objective to facilitate the entrance of young people from a neighborhood in Fortaleza which presents high levels

1 Universidade Federal do Ceará (UFC). Fortaleza, Ceará, Brasil. Av. da Universidade, ${ }^{\circ}$ 2.853 - Benfica. CEP: 60.020-181.

2 Este artigo contou com a colaboração de José Antonio Gabriel Neto, Mestre em Educação
} pela UFC. 
of unemployment, violence, and drugs, into the University. Analyzing the research data on this experience, we discuss problems in Brazilian education, related with the inclusion of young people who are out of school and labor market, aiming at real social insertion into the educational and cultural processes. Based on popular education and Paulo Freire's thoughts, we defend teachers formation in an educative context that values the cooperation and collective construction of knowledge involving teachers, monitors, and students, as subjects of educative actions.

Keywords: popular education; youth; schooling; teacher formation.

\section{Introdução}

A presente pesquisa deriva da experiência com jovens do bairro Pirambu, em Fortaleza/CE. Com apoio da Inter-American Drug Abuse Control Comission (Comissão Interamericana de Controle do Abuso de Drogas/Organização dos Estados Americanos - CICAD/OEA) ${ }^{3}$.

Nosso maior objetivo neste projeto é o de educar e apoiar os jovens de periferia urbana que estão fora da escola e do mercado de trabalho, que desejam continuar seus estudos e entrar numa universidade. Dentre seus participantes, encontramos esses jovens, aproximadamente entre 18 e 24 anos, que concluíram o ensino médio e ainda não participam do mercado formal de trabalho. Como educadores e professores das disciplinas, voluntários ou bolsistas de extensão, encontramos alunos da Universidade Federal do Ceará (UFC) que são moradores do bairro ou da região e que a ele retornam para contribuir com a educação de seus pares.

Temos como outro objetivo importante o trabalho e a iniciação profissional dos nossos monitores e colaboradores, contribuindo com os aspectos teórico-práticos de sua formação como futuros profissionais da educação. Estes exercem funções como professores das diversas áreas do conhecimento e alternadamente como coordenadores pedagógicos num processo educativo, onde realizam sua preparação para o trabalho docente. Esse é o caso particular de nossos colaboradores que realizam seus estudos universitários em cursos de licenciatura. Todo esse processo educativo contribui também para o desenvolvimento de qualidades como liderança e organização.

3 Este projeto obteve ajuda financeira da CICAD/OEA no intuito de facilitar a interação entre a Universidade e comunidades de periferia de Fortaleza. Assim, apresentamos os resultados desta pesquisa em encontros da própria CICAD/OEA na Costa Rica (2009), Panamá (2010) e Equador (2012). 
É indispensável lembrar que iniciativas como essas não substituem ou dispensam o papel do Estado e das políticas públicas em suas obrigações fundamentais tais como: a) a democratização da sociedade na elaboração e realização dessas políticas públicas e sociais; b) em suas obrigações de encontrar e dispor de formas de inversão fiscal mais distributivas e democratizantes; c) inclusive no que se refere à educação de jovens e adultos, a educação pública escolar e universitária; e d) além de outras necessidades como a formação profissional e de professores e a assistência estudantil.

O bairro do Pirambu surgiu na década de 1930 e se consolidou legalmente em 1962 com a conquista da propriedade coletiva da terra após intensa luta de seus moradores e aliados. Ele se situa na parte oeste de Fortaleza, à beira mar. Tem uma população estimada em 30.000 habitantes, pelo menos, originária da migração ocorrida no final dos anos 1950. Seu surgimento e crescimento mais significativo ocorreram entre as décadas de 1930 a 1970, período que coincide com o movimento populacional que deslocou populações inteiras do campo para a periferia das grandes cidades. Modelo social desorganizado de expansão do capitalismo periférico que veio a constituir enormes desigualdades sociais e o caótico e injusto crescimento urbano brasileiro.

Em geral, sua população é constituída de pescadores, artesãos, trabalhadores da construção civil, operários, ambulantes, comerciários, pequenos comerciantes, trabalhadores informais, desempregados e subempregados, apresentando ainda elevados índices de pobreza, violência e consumo de drogas.

Outra dificuldade enfrentada pelos moradores do bairro diz respeito às oportunidades educacionais, pois os estudantes, quando não abandonam a escola prematuramente no ensino básico e concluem o ensino médio, permanecem sem nenhuma expectativa em relação à continuidade dos estudos. Ocorre então um hiato entre o fim do período escolar e a entrada no mercado de trabalho. É o momento em que ocorrem ocupações com elevada carga horária diária e baixa remuneração. Por isso o projeto se destina a apoiar jovens que estão fora da escola, fora da universidade e do mercado formal de trabalho vivendo uma ameaça potencial do mundo da violência e das drogas.

Diante desse quadro, foi criado em 2003 o projeto de Educação de Jovens e Adultos (EJA) e Pré-Vestibular Pirambu-Cidadania, por um grupo de estudantes oriundos do Projeto Coração de Estudante (PRECE). Atualmente, o projeto é registrado na Pró-Reitoria de Extensão da UFC e coordenado pelo professor Dr. Luís Távora Furtado Ribeiro de Faculdade de Educação da UFC.

O presente estudo, portanto, pretende elucidar questões sobre formação docente e os resultados das práticas na integração Universidade-comunidade a partir das práticas no projeto supracitado. 


\section{Conhecendo o Projeto Pirambu-Cidadania}

O Projeto EJA e Pré-Vestibular Pirambu-Cidadania atua desde 2003 no bairro Pirambu, em Fortaleza, desenvolvendo ações no âmbito educacional e contribuindo para que estudantes de baixa renda ingressem no ensino superior. Concomitantemente, o projeto tem como objetivos: a) realizar ações que objetivam fortalecer e ampliar seus horizontes socioculturais; b) desenvolver processos de organização comunitária, geração de renda e participação política; c) incentivar um movimento em defesa da educação e do fortalecimento da participação popular junto a jovens e adultos de baixa renda, moradores das periferias urbanas; d) contribuir com o acesso dessa população aos bens culturais e a uma formação humana emancipatória; e e) contribuir com a formação de futuros educadores, alunos de cursos de licenciatura da universidade.

Desde sua fundação, o Projeto utiliza as dependências da Igreja Presbiteriana do bairro para realização das aulas e demais atividades socioeducativas. Estamos atendendo a quarenta estudantes no turno noturno, contando com um grupo docente formado por 12 educadores (universitários da UFC e todos voluntários) e uma liderança formada no próprio projeto e engajada nas diversas atividades que são desenvolvidas.

O Pirambu-Cidadania conta com uma biblioteca cujo acervo provém de doações. Esse espaço é vital para os estudantes e professores, pois é ali que acessam informações, realizam estudos, compartilham conhecimentos e cultivam o gosto pela leitura.

As atividades das aulas acontecem de segunda a sexta-feira no horário das $18 \mathrm{~h} 00$ às $22 \mathrm{~h} 00$ e aos sábados das $14 \mathrm{~h} 00$ às $18 \mathrm{~h} 00$. Porém, a biblioteca e o local de estudos são disponibilizados em qualquer horário, dependendo da disponibilidade dos educandos. Quanto à metodologia, não há chamadas ou provas, sendo a assiduidade dos participantes explicada pelo compromisso dos educandos e equipe de educadores.

Estes novos horizontes possíveis vêm transformando a realidade local, atraindo jovens para as atividades de estudos e discussão da realidade social, política e econômica. Isto tem contribuído para a motivação e elevação da autoestima de jovens e adultos que descobriram, através das atividades educativas que realizam no projeto, que são capazes de construir um futuro melhor, com mais oportunidades e uma vida digna.

O projeto apresenta como objetivo geral promover a inclusão social e cultural de jovens e adultos de baixa renda do bairro Pirambu e da região do litoral oeste de Fortaleza. Visa, ainda, contribuir para uma formação geral reflexiva e 
emancipadora, visando a elevação sociocultural, a organização comunitária, a geração de renda e a apropriação do conhecimento. No alcance desse objetivo geral, as ações do referido projeto apresentam outras finalidades de natureza mais específica, a saber:

a) contribuir com a comunidade para o fortalecimento da educação como fator de inclusão sociocultural, acesso ao trabalho e melhoria da qualidade de vida;

b) utilizar o espaço educativo como fórum de debates, discussões e problematização dos temas econômicos, sociais, políticos e outros temas que contribuam para o desenvolvimento dos grupos;

c) fortalecer, entre os participantes, o conceito de solidariedade, compromisso comunitário, responsabilidade social e organização;

d) promover a apropriação da cultura elaborada e em processo de elaboração numa perspectiva crítico-transformadora;

e) oferecer oportunidades de geração de renda numa perspectiva coletiva e solidária;

f) possibilitar a promoção social de jovens e adultos em situação potencial de risco;

g) reforçar a luta local pelo compromisso dos governos para com a educação pública e gratuita, seja em nível básico ou superior.

Para o desenvolvimento das atividades no Pirambu-Cidadania, utilizamos como referência teórica os pressupostos da Educação Popular e da política, inspirada nos pensamentos de Paulo Freire (1987; 1996), Freitag (1988), Arendt (2010) e Gramsci (2004).

Como afirma um dos jovens educadores: assim, os conceitos de diálogo, politização e horizontalidade nos processos de interação social dão sustentabilidade a uma ação pedagógica comprometida com as transformações sociais, o respeito à diversidade cultural e o comprometimento com uma formação humana reflexiva e emancipadora. "Assim, buscamos compreender de forma panorâmica a realidade na qual estamos inseridos para que possamos nos posicionar e atuar diante da mesma".

A participação empreendida pelos participantes do projeto é outro fundamento importante na práxis pedagógica, buscando a compreensão do papel da sociedade civil frente ao Estado, buscando interagir de forma responsável e autônoma, visando a construção de espaços democráticos e contribuindo para a politização dos sujeitos.

Portanto, são esses referenciais que norteiam as práticas sociais e educativas no Pirambu-Cidadania, que, aos poucos, vem apresentando mudanças e transformações no modo de pensar e agir entre os sujeitos envolvidos em todas as suas atividades, inclusive atividades educativas de campo. 
Quanto à metodologia utilizada, ela busca respeitar a cultura e o estágio de desenvolvimento de cada sujeito envolvido no processo de construção do conhecimento. Para o atendimento aos educandos no Pré-Vestibular cooperativo, utiliza-se o recurso pedagógico de estudos em grupos, aulas interativas, discussões e debates que favoreçam a apropriação reflexiva do saber pelos educandos. Também são utilizados filmes e palestras com temas atuais e de interesse do público estudantil, sempre visando desenvolver a reflexão e a melhor compreensão social e política de todos em direção à sua promoção social.

Os estudos em grupo, ou as células, contam com a participação de estudantes monitores, que colaboram com os grupos de estudos, esclarecendo dúvidas e acompanhando o desenvolvimento de cada membro do grupo. Estes estudantes monitores são escolhidos entre aqueles estudantes que demonstram interesse em colaborar na área do conhecimento com a qual mais se identificam e que faz parte de seu estudo na universidade.

Ao contribuir com o grupo, o estudante monitor acumula uma grande experiência através do contato com estudantes e colegas e também pela responsabilidade que assumem. Isso se revela de modo bastante favorável quanto ao desenvolvimento pessoal e coletivo, refletindo-se em seu próprio desempenho quando da realização das avaliações no vestibular ou atualmente no Exame Nacional do Ensino Médio (ENEM).

\section{Ações interinstitucionais: o público-alvo e as parcerias}

Constituem nosso público-alvo os estudantes que estão concluindo ou já concluíram o ensino médio oriundos da escola pública do bairro Pirambu e demais bairros região oeste de Fortaleza, bem como todos aqueles interessados em ampliar seus conhecimentos e buscar alternativas para o enfrentamento das adversidades enfrentadas pelas populações locais.

O Pirambu-Cidadania tem como Parceiros a Igreja Presbiteriana Independente do Bairro Pirambu, que cede suas instalações físicas para as atividades desenvolvidas pelo projeto sem cobrar valor financeiro por isso. Outra parceira do projeto é a fundação Ana Lima, que atua com educação junto a crianças e adolescentes no bairro, que também cede suas instalações para realização de eventos do Projeto Pirambu-Cidadania. Contamos com o apoio da UFC, através da Pró-Reitoria de Extensão - que oferece bolsa(s) de extensão para o projeto - e com o apoio pedagógico e institucional da Faculdade de Educação da mesma universidade. 
No tocante às finanças, o Pirambu-Cidadania conta com a contribuição dos estudantes com a quantia mensal de $\mathrm{R} \$ 10,00$. Este recurso é utilizado para reprodução de material, pagamento do transporte e alimentação dos educadores, compra de alguns livros e ajuda de custo a universitários que moram no bairro e atuam no projeto, para que possam custear algumas despesas referentes aos seus estudos.

Contamos ainda como o apoio da CICAD/OEA, que vem contribuindo através de ações como: a) concessão de bolsas aos estudantes universitários atuantes como educadores no projeto; b) financiamento de eventos realizados; c) aquisição de equipamentos de apoio pedagógico; além de d) divulgação internacional dessa experiência educativa com apresentação de trabalhos em seus encontros internacionais.

\section{Atividades desenvolvidas: um pouco de história}

Uma das atividades realizadas pelo Projeto diz respeito ao Pré-Vestibular Cooperativo, atual Pré-ENEM Cooperativo, que tem se mostrado de grande relevância para as pretensões de estudantes de baixa renda que almejam ingressar na universidade. Em 2012 atendemos a quarenta estudantes, distribuídos em duas turmas. Todos realizando significativos esforços para permanecer estudando, mesmo diante das situações de dificuldades que enfrentam, como, por exemplo, a necessidade que têm de possuir renda para financiamento das despesas mínimas para a sobrevivência.

Para além das atividades do pré-vestibular, organizamos o grupo sobre geração de renda, formado por alunos que necessitavam de algum recurso financeiro para seu dia a dia. Nossa meta é que esses estudantes trabalhem em cooperação e, assim, gerem uma renda mínima para suprir suas necessidades mais essenciais e que em outra parte do tempo disponível possam dedicar-se aos estudos.

Esse grupo que começou com cinco pessoas, vem buscando ampliar-se e incorporar outros estudantes que demonstrem interesse em participar. Todavia, uma das dificuldades enfrentadas é a falta de apoio financeiro que muitas vezes inviabiliza a execução de determinados projetos idealizados pelos participantes. Em seus encontros diários de trabalho, os participantes do Geração de Renda produzem diversas peças, como bijuterias e crochê, além de pintura em tecidos e outras atividades artesanais. Todas essas iniciativas foram aprendidas em cursos oferecidos pelo projeto através tanto de parceria com outras instituições 
quanto por intermédio da colaboração voluntária de universitários da UFC. A comercialização desses produtos ocorre em feiras na beira-mar e em alguns encontros ligados à organização estudantil na UFC.

Outra atividade desenvolvida pelos estudantes do Pirambu-Cidadania é a de monitoria, ação em que os estudantes que dominam melhor algum conteúdo colaboram com outros estudantes que apresentem dificuldades de aprendizagem em alguma área do conhecimento. Isso tem dado os melhores resultados no que se refere à interação comunitária, à colaboração coletiva, ao desenvolvimento de lideranças e à melhoria do aproveitamento pedagógico.

Uma importante experiência para o desenvolvimento dos participantes é a participação nos encontros de amostra cultural que se realizam durante os encontros universitários, promovidos anualmente pela Pró-Reitoria de Extensão da UFC. Além de apresentarem suas produções, este encontro possibilita a socialização com outros grupos, enriquecendo a visão dos estudantes acerca de novas possibilidades produtivas e de comercialização desses produtos, além de conhecerem novas técnicas e inovações, o que tem se revelado de grande valia para a realização das atividades do grupo.

O grupo Geração de Renda desenvolve atividades desde o ano de 2005 e vem se constituindo como um importante espaço de aprendizado, além de ser uma alternativa para jovens que desejam estudar e sabem que seu ingresso no mercado formal de trabalho, muitas vezes, parece tornar-se incompatível com o sonho de ingressar em uma universidade.

Existem ainda outros dois grupos de atividades, objetivando tornar mais intensas e sistemáticas as discussões políticas que anteriormente aconteciam com intervalos de dois meses. São eles: o Grupo de Desenvolvimento Político e de Ação Comunitária (GDPAC) e o Grupo de Apoio ao Estudante (GAE).

Antes desses grupos, nossas discussões sobre temas sociais e políticos ocorriam bimestralmente, englobando todos os alunos e professores, onde eram escolhidos temas de interesse coletivo para serem tratados entre todos, visando a analise crítica da nossa realidade e mais ainda dos problemas do bairro e da sociedade como um todo. Atualmente, o GDPAC é formado e coordenado pelos estudantes que se interessam mais por essas discussões, formando rodas de conversas e debates sobre os assuntos já mencionados. Esses encontros contam, sempre, com a participação de professores do Pré-Vestibular, atual Pré-ENEM, também engajados nas discussões de formação geral e política. Assim, pensam e discutem sobre os problemas e propõem soluções, gerando uma produtividade de ações dentro do bairro e desenvolvendo um espírito crítico e participativo. É aqui onde trabalhamos com temas extracurriculares, entre eles os transversais, como: ética, cidadania, sexualidade, meio ambiente, alcoolismo e drogas. 
Revelando a necessidade de participação política mais ampla, recentemente realizou-se eleição para escolha de um representante do grupo para representação no Conselho Municipal da Juventude de Fortaleza. A intenção é possibilitar a inserção desses jovens nos espaços de discussões das políticas públicas de maneira que eles possam compreender melhor esse processo e assim possam reivindicar melhorias em favor dos interesses da comunidade local e da cidade como um todo. Isso lhes possibilita uma visão mais abrangente e uma participação política mais efetiva.

O GAE tem como objetivo ampliar a interação entre os estudantes, educadores e coordenadores, servindo como elo de comunicação e compreensão dos problemas pelos quais nossos alunos passam diariamente em suas vidas pessoais, levando sempre em conta a necessidade de grande parte de nossos alunos de se sentirem importantes, reconhecidos e socialmente valorizados. Esse trabalho é importante no fortalecimento da autoestima e na reafirmação diária de suas capacidades contra um meio que sempre se mostra hostil à realização de seus sonhos e de suas melhores expectativas. Além disso, o grupo desenvolveu atividades junto aos demais estudantes no tocante à orientação destes na escolha dos cursos e carreiras que pretendem seguir.

Visando conhecer as instituições da sociedade civil que atuam no Pirambu, estamos empreendendo uma pesquisa de mapeamento dessas organizações. $\mathrm{O}$ objetivo é identificar quantas instituições atuam no bairro, o que fazem e, a partir destas informações, articular uma rede de atuação, objetivando melhorar as ações desenvolvidas junto à comunidade.

\section{Formação de professores: percursos e perspectivas}

No Brasil, desde o século XVI, as primeiras práticas docentes e os modelos de ensino sofreram influência da pedagogia de saber tradicional, de caráter religioso e normativo, dada a influência dos religiosos, principalmente os jesuítas, nessa área. Havia uma centralização na figura do professor como dominador e transmissor de um saber que ele possuía, mas não necessariamente produzia (RIBEIRO, 2010).

As primeiras instituições de ensino superior brasileiras têm, por eixo fundamental, a formação técnica e de profissionais como médicos, engenheiros e advogados.

Nos cursos de formação de educadores desenvolve-se uma nova abordagem para o educador que se pretende formar através da visão de um saber 
crítico-comunicativo e de um trabalho interativo em sua prática docente. Nas universidades, foi sendo superada a formação dos especialistas em educação, substituída por uma formação mais ampla e complexa que proporciona ao profissional de educação uma prática mais consciente do seu papel social, coerente com os parâmetros teórico críticos, atualizada em sua competência técnica e compromisso político na prática cotidiana da escola. Além disso, o educador deveria ser comprometido com a educação publica de qualidade, voltada para os anseios e necessidades da maioria da população.

Percebe-se que, aos poucos, o docente está tomando consciência de que o seu papel não é de um repassador de um saber produzido por outras pessoas, mas que ele é sujeito de um saber pedagógico que é construído pelos agentes da educação e que tem características diversas e multifacetadas. A experiência docente tem tomado um papel de mais destaque e tem sido estudada como elemento renovador da prática educativa: trata-se da descoberta do papel do saber de experiência no conjunto dos outros saberes docentes.

Assim, apenas algumas décadas atrás, a formação de professores passou a ser um eixo norteador do trabalho das instituições de ensino superior brasileiras. $\mathrm{O}$ trabalho com a educação popular e a integração com as comunidades desde a iniciação na prática docente, ou seja, na graduação, é ainda mais recente. O projeto Pirambu-Cidadania, através de concessão de bolsas de extensão, pretendia aliar um pouco a Universidade e a comunidade de periferia de Fortaleza.

Portanto, chegamos às seguintes questões: qual o real impacto que ações envolvendo diretamente as comunidades adjacentes às instituições de ensino superior têm na formação docente? E qual o ganho efetivo da população local com ações de efetividade escolar?

\section{Primeiras conquistas do Projeto Pirambu-Cidadania: ampliando alternativas}

Nesses dez anos de funcionamento, obtivemos êxitos dentro do que nos propomos: 1) alguns alunos foram aprovados no vestibular da UFC. Somente no último vestibular foram quatro aprovações (curso de Letras, Biblioteconomia, Secretariado e Ciências Sociais); 2) aprovações no Instituto Federal de Educação, Ciência e Tecnologia do Ceará (IFCE), antigo Centro Federal de Educação Tecnológica do Ceará (CEFET-CE); 3) nível técnico superior; e 4) aprovação em concursos públicos. Esses dados foram apresentados sistematicamente através de participação nos encontros de extensão realizados pela UFC. 
Em 2011, tivemos como resultados quantitativos: a aprovação de dois estudantes no vestibular da UFC e três estudantes no IFCE; contabilizando cinco aprovações em concursos públicos. Além desses resultados, juntam-se outros de ordem qualitativa, como o envolvimento e participação dos estudantes que ingressaram no ensino universitário no ano anterior através da preparação no Pirambu-Cidadania que passam a colaborar como professores, alguns deles assumindo o trabalho de coordenação técnico-pedagógica dentro da escola. A quase totalidade dos estudantes que através do projeto chegaram à universidade está envolvida com as atividades desenvolvidas no projeto e tornaram-se seus colaboradores, atuando, assim, como estimuladores para que outros estudantes participem das atividades curriculares e extracurriculares promovidas no projeto. Assim, os estudantes que conseguiram aprovação na UFC estão envolvidos com as práticas educativas do Pirambu-Cidadania, ministrando aulas e acompanhando os educandos que ainda se preparam no Pré-Vestibular. Dentre esses colaboradores, destacamos os ex-estudantes: Francisco Alex S. Araújo, facilitador na disciplina de História Geral; Liliane Silva Lima, facilitadora na disciplina de Língua Portuguesa e Literatura; Natália Ferreira Lima, facilitadora na disciplina de História do Brasil e coordenadora pedagógica local; e Edilene Teixeira da Silva, exercendo função administrativa e na organização da biblioteca.

No vestibular de 2008 da UFCE tivemos mais 12 aprovações na $1^{\text {a }}$ fase e duas na segunda. Tais resultados são expressivos, pois estes estudantes demonstraram compreender a proposta do projeto, já que além da colaboração que prestam atuando voluntariamente, buscam incentivar outros jovens a continuar em busca de seus sonhos.

Jovens e até mesmos adultos que aqui chegaram depois de alguns anos sem estudar por falta de condições veem no projeto uma oportunidade para recomeçar. Esses mesmos jovens reaprenderam a lutar pelos seus ideais e a cultivar valores que os fazem sentir-se cidadãos responsáveis pelas suas escolhas.

Para os alunos de licenciatura, é uma oportunidade de conhecer, de fato, a realidade da escola e o trabalho docente. Assim, acreditamos que o projeto possibilite a real inclusão do professor na escola e agregue saberes práticos. Tardif (2002, p. 255) alerta que a epistemologia da prática não é senão “o conjunto dos saberes utilizados realmente pelos profissionais em seu espaço de trabalho cotidiano para desempenhar todas as suas tarefas".

Utilizando o conceito de Maurice Tardif, entendemos que o saber do professor só pode ser construído em meio a uma integração real entre instituições de ensino superior e escola. As duas desempenham papel formativo, trazendo ganhos a toda a comunidade escolar.

Entendemos, também, que medidas como o projeto Pirambu-Cidadania são ainda utilizadas em pequena escala e vistas com resistência por muitos 
professores formadores. Isso se deve muito em parte ao fato da não reflexão sobre a prática ou da inexistência de uma ação colaborativa entre docentes, discentes e escola. Pretendemos, assim, com o projeto supracitado e com nossa pesquisa, levar o debate sobre tais questões aos dois espaços: Universidade e instituições escolares.

Por fim, compreendemos que esse projeto é feito com jovens e para jovens, possibilitando, em larga medida, o crescimento da autoestima e de seu crescimento pessoal e profissional, a participação de parte da juventude da periferia da cidade de Fortaleza, constituindo-se em uma semente de atuação política e transformação social.

\section{REFERÊNCIAS}

ARENDT, H. A promessa da política. Rio de Janeiro: Difel, 2010.

FURTADO, R.; FURTADO, E. A intervenção participativa dos atores. Brasília, DF: INPA, 2000.

FREITAG, Bárbara. A teoria crítica, ontem e hoje. São Paulo: Brasiliense, 1988.

FREIRE, P. Pedagogia do oprimido. 17. ed. Rio de Janeiro: Paz e Terra, 1987. . Pedagogia da autonomia: saberes necessários à prática educativa. São Paulo: Paz e Terra, 1996.

GRAMSCI, A. Escritos políticos. Rio de Janeiro: Civilização Brasileira, 2004.

RIBEIRO, L. T. F. A formação docente no Brasil. In: ; RIBEIRO, M. A. P. Temas educacionais: uma coletânea de artigos. Fortaleza: UFC, 2010. p. 103-119.

TARDIF, M. Saberes docentes e formação profissional. Petrópolis: Vozes, 2002.

Texto recebido em 20 de julho de 2013.

Texto aprovado em 12 de agosto de 2013. 